small amount of a suspension of $M$. caviae and complete Freund's adjuvant was inadvertently injected into the plantar surface of the author's thumb. Within 48 hours, the whole of the terminal joint became swollen, congested and painful; at 72 hours, oral tetracycline therapy was initiated, and ..by the fourth day, the whole hand was swollen. Two days later, the swelling started to subside and gradually reverted to normal during the course of the next four weeks.

Two weeks after the accident, the author had a serum antibody level of 1 . in 20 to $M$. caviae, estimated by the metabolic inhibition technique. ${ }^{3}$ This level rose to 1 in 40 after a further two weeks. Two other people who had been working with the organism in the laboratory showed no detectable antibody level to $M$. caviae.

Although $M$. arthritidis can produce subcutaneous abscesses in rats at the site of inoculation," the majority of mycoplasmas are not associated with localized subcutaneous lesions. This laboratory accident therefore, demonstrates an unusual characteristic of a newly recorded species of mycoplasma. Apart from this observation of possibly little direct clinical importance, the incident emphasizes the need to instigate immediate treatment of similar laboratory accidents involving micro-organisms whose pathogenic effect to man is unknown.-I am, etc.,

Auriol Hint

M.R.C. Laboratory Animals Centre

Carshaiton, Surrey

1 Hill, A., fournal of General Microbiology, 1971,

Hill, A., Blackmore, D. K., Francis, R. A., 3 Taylor-Robinson, D., Purcell, 291.

and Channock, R., Purcell, R. H., Wong, D. C., 64, 91 .

- Lemcke, R. M., fournal of Hygiene, 1961, 59, 401.

\section{Allergy to Iprindole (Prondole) with Hepatotoxicity}

SIR,-Various reports exist in your correspondence columns incriminating iprindole as the causal agent of jaundice in patients under treatment for a depressive illness ( 7 February 1970 , p. 367 ; 25 April 1970, p. 238; 7 November 1970 , p. $368 ; 21$ November 1970 , p. 494). No reports appear to exist, however, where the liver cells could be considered to be undamaged prior to the drug being administered, as demonstrated by normal serum transaminases.

In this practice we have noted several cases of hepatotoxicity demonstrated clinically as jaundice or subclinically with raised serum transaminases after administration of iprindole. One such patient had been investigated for chest pain four months previously and at that time had a normal aspartate transferase level of 95 units $/ 100 \mathrm{ml}$. After taking iprindole for two weeks the aspartate transferase was 150 units $/ 100 \mathrm{ml}$ and the patient presented with shivering, and a dark urine.

No permanent changes seem to have occurred in any patients, and we have found iprindole an excellent antidepressive drug. In view of its otherwise noted freedom from side effects it would appear important to establish the seriousness of possible liver damage after this drug in assessing its true place in the physical treatment of depressive illness.-I am, etc.,

Anthony D. Clift

\section{Congenital Dislocation of the Head of the Radius}

SIR,-Two sisters with this anomaly occurring bilaterally in the absence of any other abnormality have recently been seen. A review by Almquist, Gordon, and Blue ${ }^{1}$ made no mention of the isolated anomaly occurring as a familial characteristic. The girls were aged 7 years and 18 months when first seen. Both had been full-term normal deliveries following normal pregnancies. The mother had noticed a deformity of the elder child's elbows but had accepted this as normal. In neither case was there any history of trauma and the deformities caused no disability. Seven other siblings were normal, with the exception of a brother aged 16 years with a post-traumatic subluxing shoulder. Two paternal first cousins had congenital dislocation of the hips but examination of close relatives showed no other abnormalities.

Clinically both ohildren showed cubitus valgus of $30^{\circ}$ in the elder girl and of $40^{\circ}$ in the younger (Fig. 1). The displaced radial heads were not visible but were fairly easily

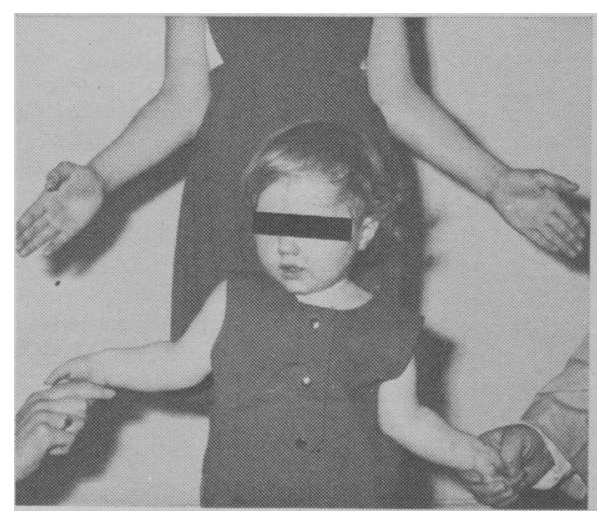

Fig. 1. The two sisters aged 7 years and 18. month respectively, showing the marked cubitus valgus.

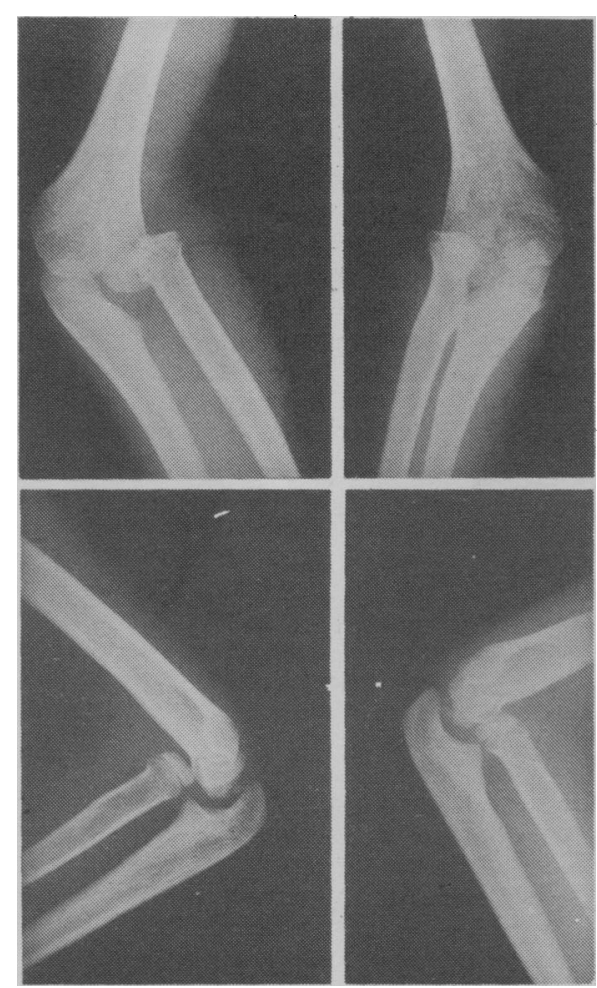

Fig. 2 Radiographs of the elbows of the elder child showing the anterior dislocation of the radial heads. The articular surfaces are convex. The capitula are well developed. palpable. In both girls flexion was from $40^{\circ}$ to $140^{\circ}$, pronation was two-thirds, and supination was only one-third of normal. No joints in either child were hypermobile. The patellae were normal and there were no abnormalities of skin or nails.

$X$-rays showed bilateral anterior dislocation in both cases. In the elder child the radial epiphyses were incompletely modelled and were convex on their articular surface. The capitula appeared well-developed (Fig. 2). In the younger child neither the radial nor capitular epiphyses had appeared (Fig. 3).
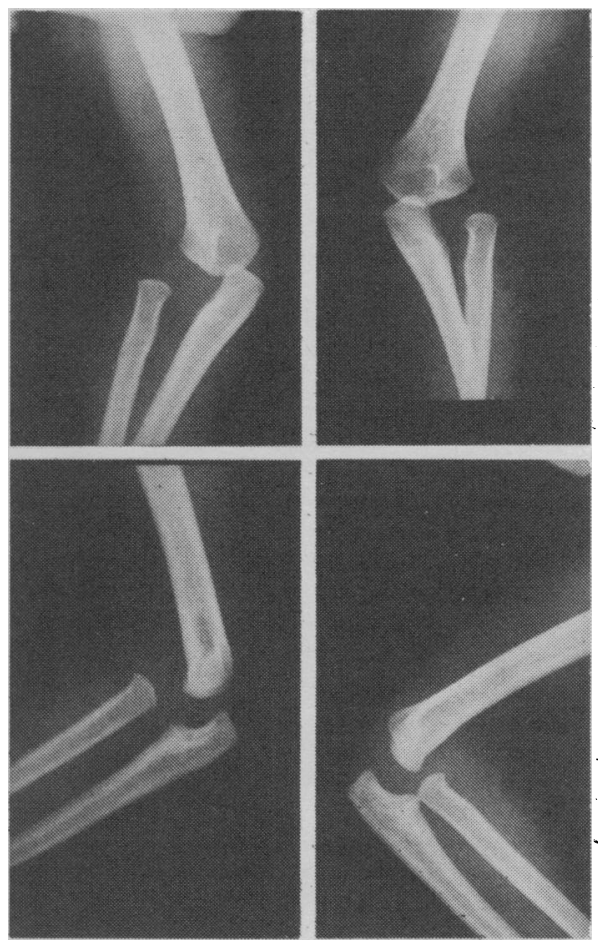

Fig. 3 Radiographs of the elbows of the younger child showing anterior dislocation of the radial

A review of the literature provides very few reports of the familial occurrence of congenital dislocation of the head of the radius. Abbott ${ }^{2}$ reported seven cases of anterior dislocation occurring in one family over four generations. No other abnormalities were described. Cockshott and Omololu ${ }^{3}$ described posterior dislocations in a father and daughter. These were thought by Mckussick to be part of the Ehlers-Danlos Syndrome. In the discussion of a paper by Fox and Griffin, Lambert ${ }^{5}$ mentioned that he had seen two sisters with the anomaly. It would appear that as an isolated familial lesion congenital dislocation of the head of the radius is very rare.

I am grateful to Mr. Malcolm Swann for permission to report his cases, which were also presented at a clinical meeting at the Royal Society of Medicine.

-I am, etc,

N. C. ROLES

Heatherwood Hospital

Ascot, Berks

1 Almquist, E. E., Gordon, L. H., and Blue, A. I.

fournal of Bone and foint Surgery, 1969, 51A. 1118.

Abbott, F. C., Lancet, 1892, 1, 800. Bone and foint Surgery, 1958, 40., fournal Bone and foint Surgery, 1958, 40B, 483.
McKussick, V. A., Heritable Disorders of Connective Tissue. 2nd edn., St. Louis, Mosby, 1960

5 Lambert, R. G., fournal of Bone and foint 